\title{
TRAb elevations occurred even in the third trimester; a case of a mother of a child with neonatal thyroid dysfunction, who received radioactive iodine therapy for Graves' disease
}

\author{
Nami Suzuki ${ }^{1)}$, Ai Yoshihara ${ }^{1)}$, Jaeduk Yoshimura $\mathrm{Noh}^{1)}$, Kazuya Kinoshita ${ }^{2)}$, Junki Ohnishi ${ }^{3)}$, Maki Saito ${ }^{4}$, \\ Kiminori Sugino ${ }^{5)}$ and Kochi Ito ${ }^{5)}$ \\ 1) Department of Internal Medicine, Ito Hospital, Tokyo 150-8308, Japan \\ 2) Kinoshita Obstetrics and Gynecology Clinic, Tokyo 124-0004, Japan \\ 3) Department of Obstetrics and Gynecology, The Jikei University Katsushika Medical Center, Tokyo 125-8506, Japan \\ 4) Department of Pediatrics, The Jikei University Katsushika Medical Center, Tokyo 125-8506, Japan \\ 5) Department of Surgery, Ito Hospital, Tokyo 150-8308, Japan
}

\begin{abstract}
Activity of Graves' disease (GD) is known to improve during gestation, as values of thyrotropin (TSH) receptor antibody (TRAb) also improve. However, the risk of neonatal hyperthyroidism increases when maternal TRAb values are high in the second to third trimester. A 29-year-old woman who had undergone radioactive iodine (RAI) therapy for GD 10 years earlier visited our hospital at 17 weeks of gestation, showing subclinical hypothyroidism and a positive TRAb value of 2.6 IU/L (reference range, $<2.0 \mathrm{IU} / \mathrm{L}$ ). Thyroid hormone replacement therapy was commenced and thyroid function normalized within 4 weeks, although TRAb was elevated at the time (3.8 IU/L). Prenatal check-up showed normal growth development and no irregularities. At 29 weeks of gestation, serum TRAb was extremely elevated, up to $16.8 \mathrm{IU} / \mathrm{L}$. Since the risk of neonatal hyperthyroidism was of great concern, delivery was planned at an advanced-care medical center. At 38 weeks 5 days of gestation, she delivered a female neonate without any complications, although blood testing of the neonate showed subclinical hyperthyroidism with positive TRAb and TSH receptor stimulating antibody (TSAb). According to the American Thyroid Association guidelines, the TRAb value should be checked in the third trimester if mothers show a TRAb elevation between the initial visit after pregnancy and 18-22 weeks of gestation. However, if the mother has a history of RAI therapy for GD, regardless of thyroid function during gestation, the possibility of TRAb values elevating over time even years after the definitive therapy must be considered.
\end{abstract}

Key words: Neonatal thyroid dysfunction, Graves' disease, TSH receptor antibody

GRAVES' DISEASE (GD) is well known to improve spontaneously as pregnancy progresses, along with decreases in the values of thyrotropin (TSH) receptor antibody (TRAb), especially in the second half of the pregnancy. This improvement could be explained by immunologic responses caused by changes in both $\mathrm{T}$ and B-cell lymphocyte subsets [1-3]. On the other hand, pregnant women with GD for whom TRAb values remain high in the late second to third trimester might be at risk of neonatal hyperthyroidism $(\mathrm{NH})$ regardless of the treatments received. Patients with GD who have a

Submitted Jan. 22, 2020; Accepted May 14, 2020 as EJ20-0039 Released online in J-STAGE as advance publication Jun. 10, 2020 Correspondence to: Nami Suzuki, MD, Department of Internal Medicine, Ito Hospital, 4-3-6 Jingumae, Shibuya, Tokyo 150-8308, Japan.

E-mail: n-suzuki@ito-hospital.jp history of definitive therapies involving radioactive iodine (RAI) therapy and surgery tend to show high TRAb values even years after these therapies $[4,5]$. Supporting those reports, the American Thyroid Association has recommended that patients treated with definitive therapies prior to pregnancy should undergo measurement of TRAb values and thyroid function during the first trimester to evaluate the risk of $\mathrm{NH}$ [6]. Furthermore, Yoshihara et al. reported that the incidence of $\mathrm{NH}$ among the children of mothers who conceived within 2 years after RAI therapy was $5.5 \%$, and the cutoff value of TRAb in the third trimester for predicting NH was 9.7 IU/L [7].

Here, we report the case of a 29-year-old woman with hypothyroidism and a history of RAI therapy for GD 10 years prior to the pregnancy, who showed an extreme elevation of the serum TRAb value in the third trimester 
of a pregnancy that resulted in subclinical NH.

\section{Case Report}

A 29-year-old female with no family history of autoimmune thyroid disease who had visited our outpatient clinic at 17 years old, presented with palpitations and tremor of the hands. Physical examination revealed diffuse enlargement of the thyroid gland $(33.7 \mathrm{~mL})$ and retraction of the eyelids and exophthalmos on both sides. Blood test on the initial visit showed hyperthyroidism with positive TRAb, resulting in a diagnosis of Graves' disease (GD). Thiamazole (MMI) was administered, but poor adherence to medication hindered recovery. At 19 years old, radioactive iodine (RAI) therapy with $177.1 \mathrm{MBq}$ of ${ }^{131}$ I was performed. Thyroid function gradually improved, and the dosage of MMI was decreased over time. Three years after RAI therapy, her blood test showed hypothyroidism with a positive TRAb value, resulting in discontinuation of MMI. Although the serum TRAb value remained positive for years, thyroid function had remained between normal and subclinical hyperthyroidism without medication. After RAI therapy, thyroid gland volume decreased $(7 \mathrm{~mL})$, and ophthalmopathy did not worsen, although mild exophthalmos remained on both sides. She first became pregnant at 26 years old, the $\mathrm{TRAb}$ value remained positive throughout that pregnancy, although thyroid function had remained normal without therapy. Neither the mother nor the neonate experienced any perinatal complications.

Ten years after RAI therapy, she again became pregnant, at 29 years old. She initially visited our clinic at 17 weeks of gestation and blood testing showed subclinical hypothyroidism, with positive result for TRAb (2.6 IU/L; ECLusys TRAb electro-chemiluminescence immunoassay, reference range, $<2.0 \mathrm{IU} / \mathrm{L})$. Thyroid hormone replacement therapy was therefore commenced with levothyroxine at $62.5 \mu \mathrm{g}$ per day. Four weeks later, when she was at 21 weeks of gestation, blood test showed normal thyroid function with a positive TRAb value. This time, the TRAb value was elevated to $3.8 \mathrm{IU} / \mathrm{L}$, and we decided to measure the TRAb value again in the third trimester while continuing levothyroxine at the same dose. Prenatal check-ups in the first and second trimester had found fetal growth equivalent to the gestational weeks, and no signs of fetal hyperthyroidism (FH), (i.e., no signs of fetal goiter or fetal tachycardia). At 29 weeks of gestation, blood testing showed a TSH value of $0.02 \mu \mathrm{IU} / \mathrm{mL}$ and the dose of levothyroxine was thus decreased to $50 \mu \mathrm{g}$ per day. Conversely, the TRAb value showed a marked elevation to $16.8 \mathrm{IU} / \mathrm{L}$. At the same time, the serum TSH receptor stimulating antibody (TSAb) value was $2,470 \%$ (TSAb radioimmunoassay and bioassay kit, reference range, $<120 \%$ ). Since the risks of $\mathrm{FH}$ and $\mathrm{NH}$ were major concerns given these results, delivery was planned at an advanced medical center with a neonatal intensive care unit. Fortunately, no signs of FH were recognized during the third trimester. At 38 weeks 5 days of gestation, a female neonate was born with a birth weight of 3,360 $\mathrm{g}$ and Apgar scores of 8 at 1 minute and 9 at 5 minutes. The delivery proceeded without any complications, although blood test of the neonate performed 4 days after birth showed subclinical hyperthyroidism (free-triiodothyronine (FT3), $3.28 \mathrm{pg} / \mathrm{mL}$; free-thyroxine (FT4), $3.02 \mathrm{ng} / \mathrm{dL}$; TSH, $0.19 \mu \mathrm{IU} / \mathrm{mL})$ with positive TRAb (8.2 IU/L) and TSAb (785\%) (Table 1) [8]. These antibodies were suspected to have been transported from the mother to the neonate across the placenta. Since the degree of hyperthyroidism of the neonate was not overt and no goiter was apparent, treatment was not required. At 76 days old, recovery of neonatal thyroid function was confirmed, body weight and height were increasing as per the standard growth curve, and neurological development appeared age-appropriate. The mother was able to be withdrawn from levothyroxine after birth and thyroid function again normalized, although the TRAb value remained positive (Table 1; Fig. 1).

\section{Discussion}

The incidence of $\mathrm{FH}$ and $\mathrm{NH}$ is between $1 \%$ and $5 \%$ in all women with active or past history of GD [9]. Yoshihara et al. reported that the incidence of $\mathrm{NH}$ among newborns of mothers who conceived within 2 years after RAI therapy was $5.5 \%$, and the only risk factor for $\mathrm{NH}$ was a TRAb value in the third trimester [7], although their study subjects were followed for only 2 years. Even though our patient had a history of RAI therapy 10 years prior to the second pregnancy, the serum TRAb value elevated over time during gestation, and her neonate developed subclinical NH. On the other hand, during her first gestation, the serum TRAb value did not increase over time, and increased again after delivery. This increase could be explained by the removal of immune tolerance after birth $[1,3]$. The difference between the first and second gestations was the exact values of TRAb and the changes in TRAb values. That is, the reason for the first neonate not developing thyroid dysfunction was that TRAb titers in the mother did not increase, even when positive. According to the American Thyroid Association guidelines [6], the TRAb value should be measured initially during the first trimester using a sensitive assay, and if TRAb values remain elevated at 18-22 weeks of gestation, the TRAb value should be checked in late pregnancy. However, the current case showed a mild elevation of the TRAb value from 2.6 IU/L at 17 weeks 
Table 1 Thyroid function and TRAb and TSAb values of the mother and neonate

\begin{tabular}{|c|c|c|c|c|c|}
\hline Reference ranges & $\begin{array}{c}\text { TSH }(\mu \mathrm{IU} / \mathrm{L}) \\
(0.20-4.50)\end{array}$ & $\begin{array}{c}\mathrm{FT} 3(\mathrm{pg} / \mathrm{mL}) \\
(2.2-4.3)\end{array}$ & $\begin{array}{l}\text { FT4 (ng/dL) } \\
(0.80-1.60)\end{array}$ & $\begin{array}{c}\text { TRAb (IU/L) } \\
(<2.0)\end{array}$ & $\begin{array}{c}\text { TSAb }(\%) \\
(<120)\end{array}$ \\
\hline \multicolumn{6}{|c|}{ Mother: Gestational period } \\
\hline 17 weeks & 5.35 & 2.1 & 0.86 & 2.6 & - \\
\hline 21 weeks & 0.42 & 2.5 & 1.15 & 3.8 & - \\
\hline 29 weeks & 0.02 & 3.0 & 1.35 & 16.8 & 2,470 \\
\hline 35 weeks & 0.18 & 2.0 & 0.92 & 17.8 & - \\
\hline \multicolumn{6}{|c|}{ Postpartum period } \\
\hline 2 months & 0.82 & 2.8 & 0.96 & 15.8 & - \\
\hline \multicolumn{6}{|c|}{ Neonate: Postnatal period } \\
\hline 4 days* & 0.19 & 3.3 & 3.02 & 8.2 & 785 \\
\hline 76 days & 5.47 & 3.2 & 1.10 & - & - \\
\hline
\end{tabular}

* Reference values and ranges of each item at 4 days old (Kawahara et al. 2002 Clin Pediatr Endocr; 11: 1-9) TSH $1.91 \mu \mathrm{IU} / \mathrm{L}(0.65-5.57 \mu \mathrm{IU} / \mathrm{L}) ;$ FT4 $2.55 \mathrm{pg} / \mathrm{mL}(1.81-3.29 \mathrm{pg} / \mathrm{mL}) ;$ FT3 $3.91 \mathrm{ng} / \mathrm{dL}(2.65-5.17 \mathrm{ng} / \mathrm{dL})$

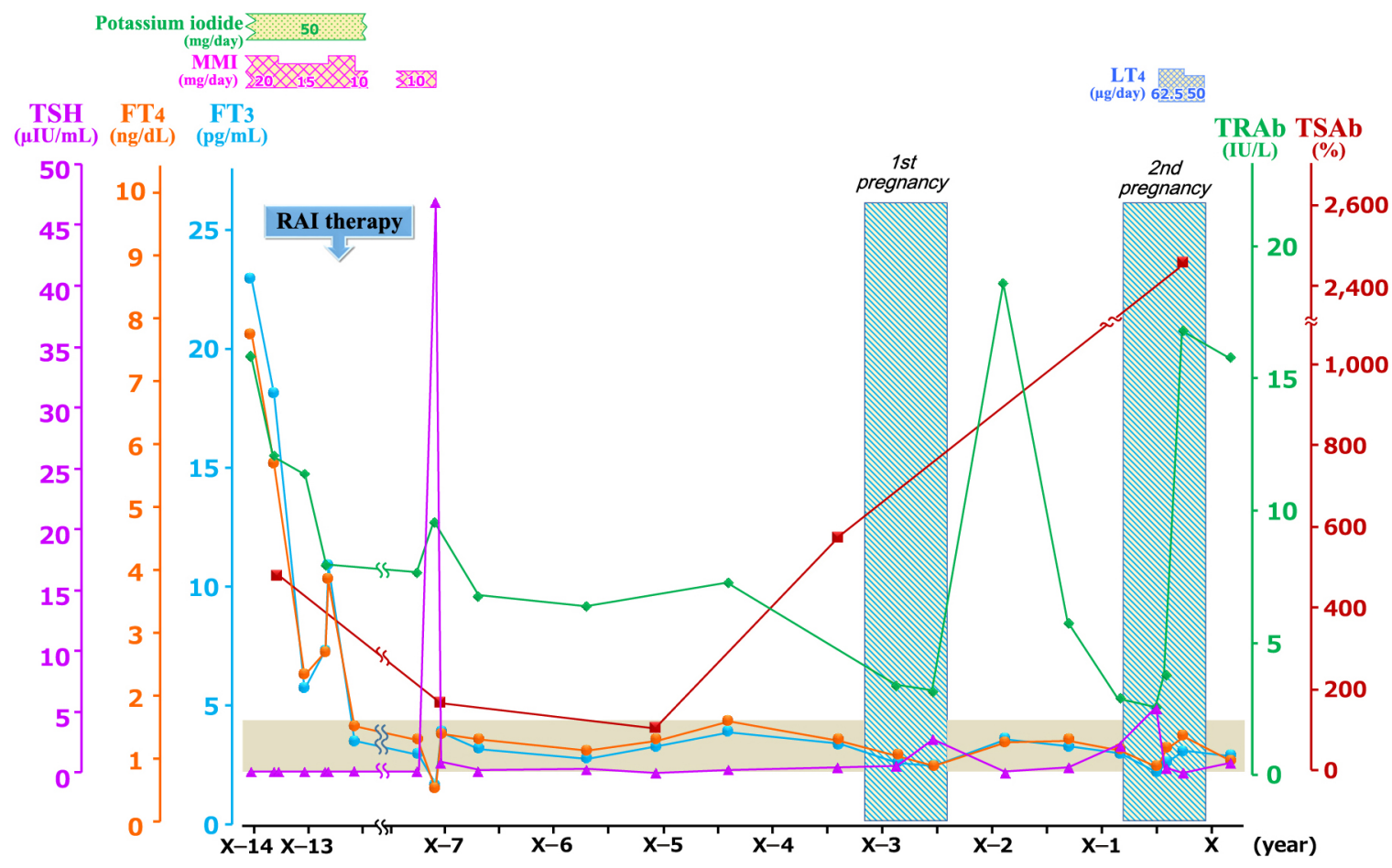

Fig. 1 The clinical course of thyroid function and TRAb and TSAb values in the mother. Thyroid function stabilized after RAI therapy, although values of TRAb and TSAb remained positive for more than a decade.

of gestation to $3.8 \mathrm{IU} / \mathrm{L}$ at 21 weeks of gestation, and predicting the development of $\mathrm{FH}$ or $\mathrm{NH}$ was difficult at that period. In addition, thyroid function of the mother suggested subclinical hypothyroidism that needed thyroid hormone replacement therapy from the second trimester, although she had been free from anti-thyroid pharmacotherapy for more than 8 years.

Moreover, a review article from the Netherlands reported that the lowest TRAb values in the mothers of children with $\mathrm{NH}$ were equivalent to 3.7 times higher than the upper limit of normal [10]. Although our patient experienced an elevation in the TRAb value between the initial visit and the second trimester, the TRAb value was less than double the upper limit of normal at 21 weeks of gestation. In the third trimester, however, the TRAb value skyrocketed to $16.8 \mathrm{IU} / \mathrm{L}$, more than 8 times the upper limit of normal. The cause of this elevation remains unclear. However, in the circumstance of high levels of estrogen (E2), as seen during pregnancy, E2 would inhibit the development of T-helper -1 cells (Th1), and promote the development of T-helper -2 cells (Th2). This change could lead to amelioration of Th1-mediated 
disease and worsening of Th2-mediated disease, such as systemic lupus erythematosus [2]. Moreover, Amino et al. reported that due to the changes in proportion of both Th1 and Th2 levels during pregnancy, an increase in TSAb activity rarely occurred [11]. This could be one explanation for the increase in TSAb during pregnancy in the present case. However, as their results were based on experiments in mice, it is uncertain whether the same mechanism applies in humans. The important point in the present case is that even when the maternal thyroid function is normal or shows hypothyroidism, TRAb elevation may occur in late pregnancy among patients with a history of RAI therapy.

Treatment for $\mathrm{NH}$ is not always necessary for infants with $\mathrm{NH}$. However, treatment should be initiated if the infant shows both biochemical hyperthyroidism with FT4 values in the range of $43-154 \mathrm{pmol} / \mathrm{L}$ and hyperactive symptoms, such as tachycardia, hypertension, or poor feeding [12]. Otherwise, treatment may not be required. In our case, although the baby was diagnosed with subclinical $\mathrm{NH}$ from blood tests performed at 4 days old, the FT4 value of $3.02 \mathrm{ng} / \mathrm{dL}(38.87 \mathrm{pmol} / \mathrm{L})$ did not exceed the recommended threshold for initiating treatment [8]. The reason for the mild thyroid dysfunction of the neonate despite the high TSAb values is uncertain. A difference in the sensitivity for the stimulation from antibodies between the mother and the child might be the reason for the mild clinical course of thyroid dysfunction of the neonate. Blood test performed at 76 days old subsequently confirmed the normalization of neonatal thyroid function. This suggests that although the neonate had hyperthyroidism, the degree of $\mathrm{NH}$ was not overt. However, from the view point of the potential risk of developing overt hyperthyroidism after birth in this neonate, more cautious follow-up of neonatal thyroid function tests should have been conducted.

In conclusion, we should be aware when encountering patients with GD and a history of RAI therapy that TRAb elevations can occur even in the third trimester as a result of Graves' autoimmunity, regardless of thyroid function.

\section{Disclosure Statement}

None of the authors have any potential conflicts of interest to disclose in association with this case report.

\section{References}

1. Weetman AP (2010) Immunity, thyroid function and pregnancy: molecular mechanisms. Nat Rev Endocrinol 6: 311-318.

2. Polese B, Gridelet V, Araklioti E, Martens H, Perrier d'Hauterive S, et al. (2014) The endocrine milieu and CD4 T-lymphocyte polarization during pregnancy. Front Endocrinol (Lausanne) 5: 106.

3. Aluvihare VR, Kallikourdis M, Betz AG (2005) Tolerance, suppression and the fetal allograft. $J$ Mol Med (Berl) 83: 88-96.

4. Laurberg P, Wallin G, Tallstedt L, Abraham-Nordling M, Lundell G, et al. (2008) TSH-receptor autoimmunity in Graves' disease after therapy with anti-thyroid drugs, surgery, or radioiodine: a 5-year prospective randomized study. Eur J Endocrinol 158: 69-75.

5. Teng CS, Yeung RT, Khoo RK, Alagaratnam TT (1980) A prospective study of the changes in thyrotropin binding inhibitory immunoglobulins in Graves' disease treated by subtotal thyroidectomy or radioactive iodine. J Clin Endocrinol Metab 50: 1005-1010.

6. Ross DS, Burch HB, Cooper DS, Greenlee MC, Laurberg P, et al. (2016) 2016 American Thyroid Association Guidelines for Diagnosis and Management of Hyperthyroidism and Other Causes of Thyrotoxicosis. Thyroid 26:
1343-1421.

7. Yoshihara A, Iwaku K, Noh JY, Watanabe N, Kunii Y, et al. (2019) Incidence of neonatal hyperthyroidism among newborns of Graves' disease patients treated with radioiodine therapy. Thyroid 29: 128-134.

8. Kawahara K, Yokota S (2002) Establishment of reference intervals of thyrotropin and free thyroid hormones during the first week of life. CPE 11: 1-9.

9. Alexander EK, Pearce EN, Brent GA, Brown RS, Chen H, et al. (2017) 2017 Guidelines of the American Thyroid Association for the Diagnosis and Management of Thyroid Disease During Pregnancy and the Postpartum. Thyroid 27: 315-389.

10. van Dijk MM, Smits IH, Fliers E, Bisschop PH (2018) Maternal thyrotropin receptor antibody concentration and the risk of fetal and neonatal thyrotoxicosis: a systematic review. Thyroid 28: 257-264.

11. Amino N, Izumi Y, Hidaka Y, Takeoka K, Nakata Y, et al. (2003) No increase of blocking type anti-thyrotropin receptor antibodies during pregnancy in patients with Graves' disease. J Clin Endocrinol Metab 88: 5871-5874.

12. van der Kaay DC, Wasserman JD, Palmert MR (2016) Management of neonates born to mothers with Graves' disease. Pediatrics 137. 